\title{
Francia para los franceses: Populismo europeo
}

\author{
Editado por/Edited by: Gabriela Albuja \\ Recibido/Received: 26/01/2014. Aceptado/Accepted: 15/05/2014 \\ Publicado en línea/Published on Web: 10/09/2014
}

\author{
Jhonny Paúl Alcívar \\ Universidad San Francisco de Quito, Colegio de Ciencias Sociales y Humanidades COCISOH \\ Diego de Robles y Vía Interoceánica, Quito, Ecuador \\ Correo electrónico: jhonny.alcivar@estud.usfq.edu.ec \\ Este artículo se terminó de escribir semanas antes de celebrarse las elecciones al Parlamento Europeo, en mayo de 2014.
}

\section{Resumen}

Ante la inacción de la clase política y la impopularidad de la Unión Europea, sumida en crisis, los partidos populistas en Europa han aumentado en votos y aceptación popular al recoger las demandas de la población mediante un discurso anti-sistema, nacionalista y anti-globalización. El Frente Nacional (FN), movimiento político francés de extrema derecha liderado por Marine Le Pen, es un visible ejemplo del populismo europeo que se encuentra en su mejor momento, aún superando a los partidos tradicionales en apoyo popular. El Frente Nacional y su fortalecimiento sumado a la abstención refleja la inconformidad de los franceses y europeos hacia el modelo de Bruselas, minando la integración.

Palabras clave: Unión Europea, populismo, Francia, Frente Nacional, globalización, Marine Le Pen, elecciones europeas.

\section{Abstract}

Given the failure of the political class and the unpopularity of the European Union, plunged into crisis, the populist parties in Europe have received increasing popular acceptance by collecting the people's demands with an anti-system, nationalist and anti-globalization discourse. The French National Front (Front National, in French), a far-right political movement led by Marine Le Pen, is a visible example of European populism is at its best, even surpassing the traditional parties in popular support. The reinforcing National Front, along with popular abstention, reflects the discontent of the French and the Europeans towards Brussels and its model, thereby undermining integration.

Palabras clave: European Union, populism, France, National Front, globalization, Marine Le Pen, European elections.

Las elecciones al Parlamento Europeo se celebrarán entre el 22 y el 25 de mayo de este año. Se elegirán, con voto universal directo, a los diputados europeos que formarán la Eurocámara. Los partidos del viejo continente alistan estrategias y nombres. Entre ellos están los partidos insurgentes -léase populistas- que aspiran tener el mayor éxito político y respaldo popular como nunca antes desde la Segunda Guerra Mundial. Ese voto del cual se están apoderando, es un voto indignado canalizado y direccionado hacia los extremistas, quienes lo han sabido administrar bien. Las elecciones próximas, aunque de nivel nacional, tienen efectos continentales, dentro y fuera de un Parlamento que adquiere cada vez más poder. Los partidos extremistas se promulgan antieuropeos - anti Unión Europea- y buscan quitarse la fachada de fascistas para lograr así un recibimiento masivo.

Del mismo modo, Francia, el país de los Derechos del Hombre, de las revoluciones, de los apoderamientos ciudadanos, de pensadores y filósofos, de movimientos progresistas, de Libertad, Fraternidad e Igualdad, vive una crisis. Una crisis social, económica y política que irrumpe al hexágono, una crisis que ha socavado los valores de la República, considerados sagrados por los franceses, y que al mismo tiempo ha propiciado las condiciones necesarias para un caldo de cultivo de ideologías populistas. El estandarte de esta corriente lo lleva el Frente Nacional (FN) con su líder, Marine Le Pen, candidata a la Presidencia del Parlamento Europeo.
Es de saber que los partidos populistas tanto en Francia como en Europa han estado activos por décadas, pero ahora gozan de popularidad al ser beneficiados por varios fenómenos actuales como la crisis económica y financiera, la carencia de representatividad política, la inseguridad, la migración, las cada vez más impopulares decisiones de Bruselas que, combinadas con un sentimiento de nacionalismo e identidad ambiguo, hacen que los partidos de ultra-derecha, con su ideología antisistema, ofrezcan soluciones convincentes para la población. No obstante, el surgimiento de estos partidos pone en riesgo la validez de la democracia y el carácter progresivo del bloque económico más poderoso del mundo.

\section{EI populismo europeo}

Básicamente, el populismo es más "una actitud política, retórica o práctica que una ideología, programa o partido" (European Humanist Federation, 2013). El populismo, ya sea de izquierda o derecha, al ser un término político, tiene una variedad de definiciones multidisciplinarias. Se puede estipular características recurrentes dadas por la European Humanist Federation, especialista en análisis de esta naturaleza.

- Promueve democracia directa a manera de relación inmediata entre el gobierno y el pueblo, rechazando el sistema político establecido. 
- Ofrece soluciones claramente demagógicas e inmediatas a los problemas comunes del de la población.

- Forma un dualismo entre el pueblo (que viene a tener el papel de bueno) contra las élites y el gobierno (acusados de ser corruptos y tecnocráticos).

- Idealiza a la nación y la exalta las tradiciones, así como el desprestigio de toda estructura supranacional (European $\mathrm{Hu}-$ manist Federation, 2013).

Cabe recalcar, como una nueva característica en estos movimientos, un discurso contra la globalización. En el caso particular de Francia con la corriente Chauvinista, la globalización afecta el sentido de su excepcionalidad cultural, doctrina explotada por los partidos de derecha e izquierda.

En este caso particular, la crisis del Euro, el problema no es a nivel de un Estado sino que abarca la confederación de 28 países. En Europa ha habido una integración monetaria pero no una integración fiscal. Los impuestos siguen siendo soberanos de cada Estado y de hecho muy distintos. Es discutible si ha habido una integración de políticas económicas y la integración política se está llevando a cabo (con demasiado o demasiado poco éxito en función del europeísmo de cada cual) con la Comisión, el Parlamento y el Consejo de Europa. Más de 5 años en crisis, ya no solo económica sino política también por la incompetencia en la clase política, ha conllevado a una insatisfacción general por la unión continental. Esto es lo que genera el apoyo a ideas populista contra el poder establecido.

"Fácilmente, el voto de protesta que está creciendo puede transformarse en populista" (Mora, 2013). Así defiende un respetado columnista español al fenómeno del populismo en crecimiento. En la historia, netamente el populismo fue un movimiento ruso del siglo XIX que luchó contra el zarismo, defendía el apoyo al pueblo y el regreso a las comunidades agrarias tradicionales. Según el Diccionario francés de Economía y Ciencias Sociales, "El populismo es un ideología política o (más bien) actitud política que es de ciertos movimientos políticos que se refieren al pueblo para oponerse a las élites que acaparan el poder y traicionan los interés de la mayoría".

Es curioso cómo una palabra tan importante para la democracia como lo es pueblo (demos) tiene una apreciación mala al utilizar la palabra populismo porque ésta se relaciona con demagogia. La propia palabra, 'democracia', ha sido banalizada en concepto en Europa; es el destino y el camino y esa imprecisión permite propuestas antidemocráticas populistas (Mény, 2005). Entonces, la democracia no es (no debería) ser capitalismo con elecciones, simplemente. Tomando en cuenta que existen tantas democracias como países que las practican, a manera de homogenizar, el Estado debe combinar ésta con un Estado de Bienestar, de Derecho, y garantizar la ciudadanía a las minorías (Mény, 2005). Caso contrario, la democracia queda en el limbo y a merced de falsas interpretaciones. La democracia son formas, son instituciones, son procedimientos.

Los populistas europeos han acogido a la democracia como valor, a manera de reivindicar la representatividad perdida al pueblo por parte de los partidos tradicionales. "El populismo, como muchos otros conceptos, es en sí mismo un cascarón vacío que puede ser llenado y dotado de sentido por cualquier cosa que se ponga en su interior" (Mény, 2005). Como dice el autor de "Populismo y Democracia en Europa", el sintetismo que tiene el populismo lo hace difícil de encasillar y predecir, lo único seguro es que representará al pueblo.

Ahora, si se habla del pueblo como un entero relacionado al país, se estará considerando el concepto de nación-estado como defendible por los populistas. ¿La concepción de un gobierno europeo tendría validez sin un pueblo europeo representado? Si se habla de etnicidad/identidad europea, entonces sí, pero al hacerlo, se desvincula a los extranjeros del proceso democrático. Es el razonamiento de los populistas para estar en contra de la migración y estar a favor de un proteccionismo nacionalista de cada país.

Al populismo siempre se lo ha vinculado, en casi su totalidad, como una característica de Latinoamérica o de países del Sur (el Peronismo argentino, por ejemplo). No obstante, en los últimos años y potencializados por la crisis, Europa ha experimentado discursos populistas por parte de nuevos líderes. Si bien el populismo o, según autores, 'neopopulismo' en Europa no es el mismo que el de Latinoamérica, en donde se utiliza medidas al extremo políticas y demagogas, el europeo también tiene un afán desestabilizador en contra del poder. Pero si política tiene que ver con el poder, cómo alcanzarlo y cómo ejercerlo, entonces no hay nada más político que el populismo.

Existen varios ejemplos: en Holanda, Geert Wilders lidera el Partido para la Libertad; en Reino Unido, el Partido de Independencia de Reino Unido tiene a Nigel Farage como líder; Le Pen en Francia lidera el Frente Nacional; en Grecia, el neonazi griego Aurora Dorada; el Partido Progresista de Noruega; el Jobbik húngaro... Éstos ven a la clase media como su motor y se encuentran en desacuerdo con los ricos y pobres, por evadir responsabilidades y por minar el Estado de Bienestar, respectivamente (The Economist, 2014). Aunque divergen en propuestas y concepción del Estado, no son similares al estadounidense Tea Party (The Economist, 2014).

\section{El caso populista francés}

El caso de Francia con el "lepenismo" y el Frente Nacional (FN) es un ejemplo claro de lo que ocurre en la mayoría de Europa, con la popularidad de los partidos anti-sistema. Tres premisas son claras para estos, y son sus tres ejes de acción: (1) "Francia para los franceses" (promulgan un discurso anti-migración), (2) Made in France (defienden una doctrina nacionalista, anti-globalización y anti-Unión Europea) y (3) Raíces cristianas de Francia (afirman las tradiciones y la identidad cristiana como absoluta en Francia). El FN no se basa en la adhesión en un programa político bien definido, sino a la negación de lo que existe.

"El holocausto fue un detalle de la Historia" o "Las razas humanas son desiguales", son dos de las frases más icónicas y polémicas del Jean-Marie Le Pen (1928), un ex paracaidista del ejército francés quién fundó en 1972 el FN, de derecha nacionalista, clasificado como de extrema derecha por la clase política francesa. Es un hombre tan polémico como atrevido en sus discursos anti-sistemas y al mismo tiempo es una figura importante en la política gala. Junto a su movimiento (el FN se reúsa a ser llamado partido político) alcanzó la segunda vuelta en las presidenciales del 2002 luego de ganar al Partido Socia- 
lista, todo un acontecimiento. Luego en 2011, pasó el testigo a su hija menor Marine Le Pen. Ella, por su parte, terció en las presidenciales de 2012 quedando, para sorpresa de todos, en tercer lugar. El apellido ni las ideas no acaban ahí, ya que Marion Maréchal-Le Pen, nieta de Jean-Marie y sobrina de Marine fue electa para la Asamblea Nacional en las legislativas de 2012, consecuentemente logrando dos hitos: ser la primera representante en la Cámara Baja del partido que fundó su abuelo desde 1988, y con sus veintidós años, ser la asambleísta más joven de la historia moderna francesa. Por este hecho se define como la representante de las juventudes francesas.

Ahora, el gobierno socialista, encabezado por François Hollande, cuenta un respaldo cada vez más bajo (19\% de aceptación en enero de 2014 según reveló el diario Le Monde) lo cual abre un problema de representación de los franceses que, descontentos, ven cómo su situación económica no mejora, la vida se encarece y su sacrosanto Estado de Bienestar se ve dilapidado con políticas de corte liberal como la disminución en $€$ 50 mil millones la asistencia social hasta 2017 (Guélaud, 2014). Esta situación es bien capitalizada por el $\mathrm{FN}$, quienes mejoran cada vez en votos y que buscan llevar gran número de eurodiputados a Bruselas; al mismo tiempo se proclaman como la primera oposición del gobierno y la primera fuerza política en Francia (40\% de intención de votos, según encuestas oficiales de enero). Nunca en la V República un partido extremista ha logrado tal cantidad de apoyo. Siempre se ha podido reflejar mucho la tradición francesa antisistema que ha oscilado alrededor de un $20 \%$, si se habla de los comunistas, con los trotskistas y los tradicionalistas.

Como lo nombra El País de España, el FN es "El partido más pujante y en boga de Francia" (Mora, 2013). Ya en las presidenciales del 2012 sus ofrecimientos calaron en la población, en particular jóvenes y obreros, dos sectores muy sentidos y desamparados por la crisis en la Unión Europea que va al quinto año, quienes ven con esperanza a este movimiento como uno de ellos y que sabe sus necesidades, contrarios a los partidos fuertes: el Partido Socialista (PS) del actual presidente Hollande y el derechista Unión por un Movimiento Popular (UMP) del ex presidente Nicolás Sarkozy.

\section{El perfil de un radical populista y su propuesta}

Se necesitaría un análisis exhaustivo para comprender o intentar comprender a Marine Le Pen. Su discurso ha calado en la desairada, molesta y siempre muy exigente sociedad francesa. Una ultra que heredó de su padre un verbo y discurso feroz y eficaz con un sarcasmo y demagogia recurrente es Madame Le Pen. Esta mujer de política tiene principios anti-europeos, anti-sistema, anti-partidos, anti-globalización, anti-mercado, anti-islam, anti-gitano (en sí, anti inmigración) y posiblemente homofóbico (en rechazo de la Ley del Matrimonio entre personas del mismo sexo y por el apego a grupos conservares cristianos); nacionalista-proteccionista y de derecha ambigua. Dijo una vez, entre sus frases polémicas que, "La escuela no tiene que dar clases de lengua y cultura extranjera. El rol de la escuela pública laica, pública y republicana es el de fabricar franceses" (Mora, 2013).

Por el momento, su discurso y sus ideas, en palabras del filósofo Eric Fassin, "son defendidas desde el poder y desde la oposición" (Mora, 2013). Entre sus propuestas, que son bastante similares a las de sus pares en otras latitudes europeas, están el cierre de las fronteras comerciales de Francia; la aprobación de leyes que protejan la producción nacional; y un plebiscito para salir del Euro y la Unión Europea, que a su manera de ver solo protege a la banca y perjudica a los ciudadanos.

Esas formulaciones demagógicas contra el poder -léase oligarquía política y financiera- son muy características de un populista. El tan republicano "Libertad, Igualdad, Fraternidad" se pone en peligro por la influencia ultra. Las marchas multitudinarias contra migrantes y el desacuerdo al matrimonio homosexual en las principales ciudades del país del hexágono van en aumento. Le Pen y su movimiento, ahora, buscan socios que compartan el discurso de extrema derecha y los van encontrando poco a poco en una Europa sumida en la crisis.

\section{Voto sanción}

Es necesario sobre todo, poner el contexto que la popularidad del Frente Nacional (FN) es relativa. En Francia existe un hartazgo hacia la clase política, en particular al gobierno y partido político. Este sentimiento se traduce en un ausentismo histórico en las urnas como se evidenció en las recientes elecciones municipales, con menos del $60 \%$ de participación ciudadana. Luego, si se toma al elector francés se verá que el FN lleva su cuota de aceptación mayoritaria en áreas periféricas y rurales del país, mas no en grandes urbes. Los llamados perdants de la globalisation (perdedores de la globalización), que es parte de la población que vive en las periferias de las grandes ciudades o alejados en el campo o muy al norte o muy sur de Francia es el electorado que más se siente golpeado por "amenazas externas" y conceden el voto al partido de Le Pen. El FN tiene cualidades de un catch-all party por su carácter receptor de toda clase de población, inclusive de migrantes, a quién ataca en su discurso.

\section{Contexto galo}

Final del partido, Francia campeón mundial de fútbol. Era en ese entonces 1998 y en los Campos Elíseos, las encantadas multitudes festejaban -y aceptaban, de hecho- una nueva Francia, mestiza y mezclada. Una flamante nueva identidad, la France black, blanc, beure. La composición demográfica diversa y multiétnica representada en el equipo nacional daba una pauta exitosa. Después de todo, el capitán, Zinedine Zidane era un francés de origen argelino. Es así que los black (refiriéndose a los franceses de descendencia negra emigrados de las antiguas colonias en África); los blanc, (los franceses "tradicionales" caucásicos-europeos) y los beure, del argot francés arabeu, o árabe en español (describiendo a los franceses de origen magrebí) formaban ya una Francia muy distinta a aquella de los personajes galos que luchaban contra los romanos, caricaturizados con Asterix \& Obelix: rubios, de tez blanca y ojos claros.

¿Qué es ser francés? En el derecho galo, la nacionalidad viene respaldada bajo los contextos jurídicos del ius sanguinis (derecho de sangre) y del ius solis (derecho del suelo). Significa que una persona será francesa si tiene padre y/o madre francés, o si, en su defecto, es de origen extranjero nacido en Francia. Por siglos, este país europeo ha sido el ejemplo de la aceptación de migrantes como suyos y hasta no hace poco, así lo seguía siendo. La crisis llegó. Los franceses que comen carne halal ya no son tan franceses, la aceptación a los migrantes o 
descendientes de ellos se ha reducido notablemente y existe un ambiente de intolerancia poco visto en el país. Es lo que profesa Le Pen y es lo que los partidos fuertes tratan de imitar.

De hecho, en el hexágono cohabitan de facto distintas culturas provenientes de todas las latitudes, mas esto no se relaciona con un modelo multicultural como en Norteamérica. El modelo Republicano Francés no se fundamenta en la aceptación como diferentes, sino en la asimilación cultural de los inmigrados, justificando una igualdad total. Para la República se es francés o no.

Los términos de extrema derecha y populismo son ambiguos y de varias interpretaciones. No obstante, las características mostradas por los movimientos extremistas europeos, con el FN como ejemplo, dan claras muestras de una falta de política dirigida a preservar los valores republicanos. Del otro lado, existe división y desigualdad que, lejos de ser criticadas, son acogidas por una Europa aturdida por una crisis que pareciera interminable. El FN llega a las elecciones europeas a la cabeza de las encuestas con un $24 \%$, si bien no son elecciones presidenciales ni legislativas. Su discurso de que los europeos no existen es aceptado por ya una parte visible de los franceses, mostrando así un fenómeno social creciente, reflejo de otros fenómenos sociales en la población europea y francesa que buscan solución y un cambio de pensamiento. Un sismo político puede llegar a desatarse.

\section{Referencias}

Un sondeo da el 34\% de popularidad al Frente Nacional de Marine Le Pen. (12 de Febrero de 2014). Recuperado el 10 de Marzo de 2014, de El País: http://internacional.elpais.com/ internacional/2014/02/12/actualidad/1392194676_177828. html

Guélaud, C. (15 de Mayo de 2014). Croissance: la contre-performance française. Recuperado el 15 de Mayo de 2014, de Le Monde: http://www.lemonde.fr/economie/article/2014/05/15/croissance-la-contre-performance-francaise_4418966_3234.html?xtmc $=$ pacte $\&$ xtcr $=9$

Mény, Y. (2005). Populismo y democracia en Europa. Metapolítica, 61-67.

Mora, M. (27 de Octubre de 2013). La cocina del Tea Party europeo. Recuperado el 10 de Marzo de 2014, de El País: http://internacional.elpais.com/internacional/2013/10/25/actualidad/1382731149_848385.html

Ortega, A. (19 de Diciembre de 2013). Tecnocracia o Populismo en Europa. Recuperado el 10 de Marzo de 2014, de El País: http://elpais.com/elpais/2013/11/15/opinion/1384545128_601654.html

Europe's Tea Parties. (14 de Enero de 2014). Recuperado el 12 de Marzo de 2014, de The Economist: http://www.economist.com/news/leaders/21592610-insurgent-parties-arelikely-do-better-2014-any-time-second-world

The European Humanist Federation. (2013). The European Union and the Challenge of Extremism and Populism. Brussels. 